\title{
IMPLICAÇÕES DA PROLETARIZAÇÃO DO TRABALHO DOCENTE NA EDUCAÇÃO FÍSICA ESCOLAR
}

\author{
Guilherme Bardemaker Bernardi \\ Rede Municipal de Ensino de Porto Alegre, Porto Alegre, Rio Grande do Sul, Brasil \\ Vicente Molina Neto \\ Universidade Federal do Rio Grande do Sul, Porto Alegre, Rio Grande do Sul, Brasil
}

\begin{abstract}
Resumo
Este artigo discute o processo de proletarização docente, mais especificamente no âmbito da Educação Física Escolar. Partindo de uma leitura materialista dialética de educação, foi realizada uma pesquisa de cunho qualitativo com professores da Rede Municipal de Ensino de Porto Alegre, no qual procuramos compreender como os professores organizam seu trabalho pedagógico frente a esse processo, que decorre da aproximação cada vez maior das condições do trabalho docente com as características do trabalho da sociedade capitalista.
\end{abstract}

Palavras-chave: Proletarização Docente; Trabalho Pedagógico; Educação Física Escolar; Materialismo Dialético.

\section{Introdução}

O presente artigo tem como objetivo compreender quais são as implicações do processo de proletarização do trabalho docente na organização do trabalho pedagógico da Educação Física escolar. A partir de uma leitura crítica da realidade, entendemos que a organização do trabalho pedagógico precisa ser entendida tanto no microcontexto da escola quanto no contexto de relações mais amplas, como concepções de ensino-aprendizagem, passando pelas estruturas curriculares, a formação profissional e, finalmente, a base material em que se inserem todos esses processos: a sociedade capitalista. Esse é o ponto de partida para discutirmos a proletarização docente como o conceito que identifica cada vez mais a categoria docente com os trabalhadores historicamente categorizados como proletários.

Realizamos um estudo no âmbito do materialismo-dialético, com elementos metodológicos da pesquisa qualitativa. Buscamos, através do diálogo com a literatura, compreender o processo de proletarização no âmbito da educação, e, através da inserção no campo de atuação de docentes da Educação Física, a escola, compreender quais elementos da proletarização docente se fazem presentes no cotidiano dos professores, bem como eles organizam seu trabalho frente a esse processo.

\section{Proletarização docente}

O ponto de partida para a compreensão do conceito de proletarização docente é a relação do ser humano com o trabalho e a partir da organização da sociedade. Para tal, nos reportamos aos escritos de Karl Marx (MARX 2007; 2010; 2012) para subsidiar essa discussão. 
O trabalho enquanto perspectiva ontológica diz respeito à sua função humanizadora. É a mediação do homem com a natureza a fim de produzir a sua existência. É somente conhecendo e interagindo com a natureza que se torna possível o ser humano constituir-se como tal, pois é ao transformar a natureza que o homem se transforma.

Pelo viés histórico, o trabalho é entendido a partir de como as sociedades se organizam e a sua divisão social. Com o advento da sociedade industrial e a ascensão burguesa como classe dominante, se concretiza o capitalismo como modo dominante de organização da vida. Desprovidos de qualquer posse a não ser sua prole, os trabalhadores são obrigados a vender a sua força de trabalho, única mercadoria que possuem, em troca de um salário, constituindo uma relação com o patrão, que constitui o processo de exploração deste sistema. Surgindo, assim, o termo proletário.

Neste sentido, a ideia de proletarização diz respeito ao avanço da contradição capitaltrabalho nas relações da sociedade capitalista, causando aumento do volume de trabalho, intensificação e precarização do trabalho de uma maneira geral.

A escola, como espaço de trabalho educativo, acaba sendo orientada pelas determinações desta sociedade. E no âmbito educacional, as relações capitalistas têm aproximado as condições de trabalho docente com as da classe operária, desde a concepção educativa até o cotidiano dos docentes.

O conceito de proletarização docente aqui utilizado, então, tenta abarcar autores que se utilizaram dele para compreender a origem do aprofundamento das relações capitalistas de trabalho no âmbito do trabalho docente. Para Fernandéz Enguita (1991), a origem da proletarização docente tem início nos processos de urbanização e criação de escolas mais complexas estruturalmente, quando se inicia uma tendência de divisão e hierarquização do trabalho dos professores. Contreras (2002) aponta que a proletarização constitui-se na subtração progressiva de uma série de qualidades que levam o professor a perder tanto o controle quanto o sentido de seu trabalho. Os processos de trabalho dentro da escola são cada vez mais específicos, e a perspectiva do todo é extinta, exigindo cada vez menos do professor uma ação intelectual, mas sim, automatizada e técnica, em que se inicia um processo de separação entre concepção e execução.

Tal conceituação nos leva a dialogar com autores que trazem as consequências da proletarização docente, tais como a intensificação e autointensificação do trabalho docente, como consequência da responsibilidade cada vez maior da figura do professor pelo fracasso escolar (GARCIA E ANADON, 2009); precarização do trabalho, com arrocho salarial, aumento de contratos temporários e cada vez menos condições de trabalho adequadas (OLIVEIRA, 2004), bem como o processo cada vez maior de adoecimento dos docentes devido à carga e sobrecarga de trabalho (DIESAT, 2009; CPERS/Sindicato, 2010).

No âmbito específico da Educação Física, o conceito proletarização docente não tem aparecido de forma central em estudos científicos. Mas nosso entendimento é que, do ponto de vista teórico, os professores de Educação Física estão, conjuntamente inseridos nesse processo de proletarização docente. Compreendemos que as diversas determinações ocorridas no trabalho docente perante este processo são muito similares para os professores das diversas áreas do conhecimento.

Entretanto, nosso objeto de pesquisa parte de um recorte específico no campo da educação física escolar, tendo em vista nossa formação e nossa área de interesse acadêmico e científico. São inúmeras as pesquisas que tratam de elementos e características que decorrem do processo de proletarização no âmbito da escola pública. São exemplos: a intensificação pela qual os professores vêm passando e que implica em diversas consequências ao trabalho dos professores, como isolamento, sobrecarga de trabalho e impossibilidade de organização e planejamento, tanto individual quanto coletivo, frente às necessidades do seu cotidiano (WITTIZORECKI, 2001); a "multiplicidade de papéis" que os professores assumem no 
contexto da escola pública, que gera um desgaste pessoal com o trabalho, e em consequência, aparecem sintomas emocionais que refletem diretamente na saúde dos professores, que comprometem e diminuem a satisfação do professorado para com o seu trabalho, levando-os à chamada "síndrome do esgotamento profissional" (SANTINI, 2004).

As características apresentadas pelos trabalhos citados podem ser incluídas dentro de um contexto de aprofundamento das relações capitalistas no interior da escola e que interferem diariamente no trabalho pedagógico dos professores de Educação Física. É partindo desse entendimento de realidade que realizamos este estudo, em que o objetivo geral foi compreender a organização do trabalho pedagógico do professor de educação física frente ao processo de proletarização docente. Como objetos específicos, compreender as implicações do fenômeno no trabalho pedagógico dos docentes; identificar o que pensam os docentes acerca das implicações da proletarização docente no seu cotidiano e compreender o processo de organização coletiva dos professores frente a esse processo.

\section{Abordagem teórico-metodológica}

Para compreender o fenômeno da proletarização docente, realizamos uma pesquisa qualitativa no âmbito do materialismo dialético. Entendemos que a inserção no local de trabalho dos docentes se faria imprescindível. Sendo assim, realizamos uma pesquisa de campo em quatro escolas da Rede Municipal de Ensino de Porto Alegre (RMEPOA). Tivemos como colaboradores cinco docentes de EFI, com os quais realizamos cerca de 40h de observações participantes de aulas e elementos pertencentes ao contexto escolar, desde nosso deslocamento até o local de observação até a nossa saída. Contamos, ainda, com a colaboração privilegiada de uma professora que fez parte da direção da Associação dos Trabalhadores em Educação de Porto Alegre (ATEMPA) no período de 2010-2013, e que também atua como professora de Educação Física em uma escola da RMEPOA. Como análise de campo, observamos duas reuniões da ATEMPA na qual a professora se fez presente. Assim, o grupo observado se constitui de seis professores.

Segundo Negrine (2004) é necessário que a observação seja intencionada com os objetivos do estudo, que seja sustentada pelo corpo de conhecimentos teóricos utilizados pelo pesquisador e que se realize no contexto real a qual se desenvolvem as suas atividades.

Realizamos uma entrevista semiestruturada com cada colaborador, de cerca de uma hora cada, pois possibilita um roteiro para o diálogo, além de ser flexível para que os participantes incluam novas questões e contribuições relevantes sobre o estudo (MOLINA NETO, 2004).

Baseando-se nas técnicas que utilizamos, criamos categorias de análise a partir do material empírico que construímos ao longo do estudo. Para dar uma sustentação epistemológica às análises, foi a realização da triangulação dos dados, que, para Triviños (1994), tem por objetivo abranger a máxima amplitude na descrição, explicação e compreensão do foco em estudo. Para isso, devem estar articulados, ou seja, triangulados, três aspectos: o primeiro são os processos e produtos centrados no sujeito (como entrevistas, observações, etc.); o segundo são os elementos produzidos pelo meio do sujeito (documentos oficiais, etc.); e o terceiro são os processos e produtos originados pela estrutura socioeconômica e cultural do macroorganismo social no qual está inserido o sujeito, a partir da teoria estabelecida. Desta forma, foi possível compreender o fenômeno de forma mais aproximada com a realidade.

As categorias surgiram a partir do agrupamento de conjuntos de significados obtidos através das entrevistas e das observações do trabalho de campo em temas afins. Tal organização teve como objetivo pontuar algumas temáticas na qual fosse possível analisar de forma mais particular o objeto de estudo e seus atravessamentos na construção do trabalho 
pedagógico dos professores de educação física. Entretanto, tivemos o cuidado para que o processo analítico das categorias não tivesse um fim em si mesmo, haja vista que, a partir da premissa da totalidade no âmbito da discussão marxista, trabalhar o tema da proletarização de modo muito segmentado seria ir de encontro com tudo aquilo que defendemos como forma de procedimento para a pesquisa científica. Dessa forma, tomamos o cuidado de transversalizar a temática da proletarização e as diferentes formas nas quais ela se apresenta na escola, no trabalho e na organização dos professores.

Sendo assim, identificamos três aspectos, que, no limite do nosso estudo, apresentaram-se como mais importantes para compreender o objeto de pesquisa, e que transversalizam o processo de proletarização: o processo de entrada na rede; a relação do professor com a autonomia e; a organização coletiva dos professores de Educação Física na escola e no sindicato.

\section{O processo de entrada na rede: os desafios do professor iniciante}

Dos seis professores de Educação Física que colaboraram com nosso estudo, dois são considerados iniciantes, segundo a definição de Marcelo (2009). Elis e Vinícius têm a RMEPOA como o primeiro contato profissional no campo da Educação após a conclusão de sua formação inicial.

Vinícius define sua entrada na RMEPOA como "relâmpago", termo que usa para caracterizar a condução apressada que teve ao trabalho:

[...] eu não tinha experiência nenhuma. E na hora que tu chega já mais pro final do ano, já em setembro, né, já me deram as turmas e eu tinha que me virar com as turmas. Lá na Escola Tom Jobim, principalmente, que eram mais turmas e elas todas eram turmas dos pequenos, de primeiro ciclo, primeiros anos do primeiro ciclo. E eu tive bastante dificuldade assim lá (Entrevista Vinícius, 13/05/2013).

Essa forma de inserção pode trazer problemas principalmente na organização do seu trabalho pedagógico, tendo em vista que assume turmas em uma escola sem um tempo necessário para conhecer o ambiente de trabalho e poder se organizar. Tal condição, entretanto, está relacionada com o atual contexto da RMEPOA, na qual há uma falta considerável de professores, devido ao alto número de aposentadorias, licenças-saúde e/ou faltas recorrentes.

Outra condição enfrentada pelos docentes iniciantes diz respeito a práticas que as escolas mantêm. Em parte das escolas da RMEPOA, os professores mais antigos têm preferência na escolha de turmas. Tal prática não tem respaldo legal, mas se constitui em uma cultura por vezes intocável dentro de algumas instituições. Freitas (2002) observou esse cenário em um estudo, ao relatar que é comum, nas escolas, delegar ao docente iniciante as turmas consideradas mais "difíceis", e que a lógica da escolha acaba sendo uma forma de "reconhecimento" aos professores mais antigos.

Por um lado, esta prática, no próprio ato de inclusão do novo docente já o marginaliza, pois the insere no "fim da fila" de uma relação de poder que se naturaliza na cultura escolar. Por outro lado, os professores mais antigos, que, devido a todo o processo de precarização do ensino público e às dificuldades inerentes ao trabalho pedagógico em situações nas quais estão inseridos na escola pública, veem nestas conquistas, muitas vezes, o "respiro" necessário para que possam seguir atuando e construindo suas estratégias pedagógicas para não abandonarem a carreira.

Evidencia-se, entretanto, uma relação de poder instaurada que não condiz com a construção de um trabalho que se proponha ser questionador e transformador de uma 
determinada realidade, que pense na autonomia e na emancipação dos seres humanos, pois o critério definidor não é pedagógico.

Tais questões confirmam o que alguns autores denominam de "choque com a realidade", como relata a professora Elis:

[...] Eu nunca havia dado aula em escola nenhuma a não ser nos estágios da faculdade. E me preparei pra dar aula conforme eu imaginava que deveria ser uma aula, né, com parte inicial, desenvolvimento, parte final. [...] eu não conseguia dar aula, porque na escola onde eu tinha 20 horas não tinha muito a cultura de aula dirigida, os alunos ficavam bastante à vontade pra escolher as atividades que iam fazer e "se" iam fazer (Entrevista Elis, 11/11/13).

A professora relata os inúmeros casos em que lhe era solicitada que "desse conta" de duas turmas juntas ou assumisse outras em seus períodos de planejamento, devido à falta de professores na escola. O que evidencia: 1) um processo de intensificação do seu trabalho, pois atende mais de uma turma simultaneamente, além de estar prejudicando a intencionalidade pedagógico do seu trabalho, e 2) extensificação do trabalho, pois acaba levando para casa as tarefas que poderia dar conta no seu período de planejamento.

Nos casos de Vinícius e Elis, nota-se um processo de organização escolar que têm se caracterizado por receber o docente iniciante, como define Marcelo (2009), "Aterrisa como puedas", que consiste, em síntese, na inexistência de uma política de acolhimento por parte das instituições de ensino com os novos docentes. Em trabalho recente, Molina Neto et al. (2013) discutem como os primeiros anos de trabalho na escola surtem efeitos na identidade, na autonomia e na formação dos professores de Educação Física. No trabalho, os autores ressaltam que não há uma política pública de acolhimento pedagógico e emocional aos professores iniciantes, o que resulta, em grande parte, em uma dolorosa iniciação. Segundo o estudo, parte dos colaboradores já está precocemente em desinvestimento na carreira docente e outra parte, ainda mantém o compromisso. Com a falta do apoio, as alternativas para superar esse período são, na maioria dos casos, individuais.

São necessárias estratégias de suporte para os novos professores, tanto na micropolítica escolar quanto na macropolítica, para que os novos professores possam se inserir de forma mais harmoniosa com um trabalho que, por si só, já é complexo, ainda mais se tratando dos primeiros anos da carreira docente.

\section{Proletarização docente e autonomia dos professores}

Com o processo de proletarização docente marcante na sociedade capitalista, a racionalização do ensino como um todo afeta, também, o trabalho do professor, reduzindo a sua autonomia diante do seu trabalho, seja porque cada vez mais esteja sob o controle de agentes externos, seja porque a estruturação escolar se aproxima cada vez mais da lógica fabril.

Não significa, entretanto, que o processo de proletarização subtraia totalmente o sentido do trabalho do professor. Apesar dessa condição, os professores ainda detêm um conhecimento intelectual importante, que não os limita a uma tarefa mecanizada. Os professores ainda possuem certa autonomia no "o que" e "como fazer" o seu trabalho pedagógico.

Concordamos com Contreras (2002), quando diz que a autonomia deve ser entendida não só como direito trabalhista, mas principalmente enquanto necessidade educativa vital. A autonomia deve ser pensada a partir de uma visão educativa transformadora e questionadora, baseada em fundamentos pedagógicos muito claros. Que não cerceie a liberdade técnica e 
ideológica do professor, mas que esteja em consonância com um projeto de Educação emancipatória.

A escola, assim, deve ser pensada como um espaço determinado por algumas condições, mas que pode ser determinante para mudar a própria condição que a determina. Segundo Franco (1988), é necessário perceber a escola como um produto histórico, e que, portanto, pode e deve ser transformada. Dialeticamente, a escola, ao mesmo tempo em que reproduz, transforma. Da necessidade de transformação é que surgem as possibilidades de construção de um trabalho pedagógico que faça o questionamento ideológico do que representa a Educação que temos na sociedade atual. Mesmo dentro das adversidades, a escola pode e deve ser disputada.

Em nosso entendimento, tem-se projetado na escola a lógica individualista da sociedade neoliberal, na qual o professor pode tanto ser o "vilão" ou o "herói". E em alguns casos, o professor toma para si, com a melhor das intenções, uma responsabilidade que não é sua, pois tenta dar conta de problemas que deveriam ser tratados com mais cuidado pelo poder público. Um exemplo disso é o relato da professora Elis, quando destaca na entrevista que em diversos momentos, devido à falta de material, comprou do próprio salário material didático para poder dar conta de sua proposta de trabalho.

Neste contexto, é possível pensarmos qual o papel da Educação Física no processo de escolarização e Educação no Brasil. Refletindo pela ótica da contradição, é possível afirmar que, enquanto área de conhecimento historicamente construída e que se legitimou no currículo escolar, tanto reproduz a lógica dominante da sociedade, através de conteúdos e concepções de ensino que corroboram para tal, quanto serve para promover um discurso e uma prática contra hegemônica, através da problematização da realidade, partindo de outra perspectiva teórica e prática.

Tal avanço teórico, entretanto, não é garantia de uma Educação Física propositiva ou distinta de outros tempos. São diversos os motivos que nos levam a criar tal hipótese, mas na limitação de nosso estudo, procuramos nos focar sobre as determinações que interferem na organização do trabalho, a partir do processo de proletarização do trabalho docente.

Discutimos como as condições materiais objetivas estão no campo das determinações de um trabalho. Bakhtin (2006) discute em que medida a ideologia determina a linguagem, e como esta linguagem ideológica também se manifesta de forma material. A partir dessa ideia, em que a realidade de um signo é objetiva, notamos o quanto a influência do esporte no campo da Educação Física acaba sendo um aspecto importante na própria organização do trabalho pedagógico, pois não interfere só no campo ideológico das instituições de formação de professores, mas, também, no aspecto material, na organização física das escolas, seja na arquitetura escolar, bem como na disponibilidade de recursos materiais para a realização das aulas: das quatro escolas observadas, todas destacam a sua organização espacial para a prática das aulas de Educação Física a partir da relação da área com o fenômeno esportivo. Algumas escolas, pelo seu tamanho, possuem apenas uma quadra, outras, possuem só o ginásio. Outras, ainda, contam com campo de futebol, ou um espaço específico para o voleibol.

Dayrell (1996), ao falar sobre a estruturação das escolas, enfatiza que o espaço arquitetônico da escola expressa uma determinada concepção educativa. Isso fica claro em uma passagem do Diário de Campo, durante nossa primeira visita à EMEF Moncada, o professor Sílvio relata dentre outras coisas, da dificuldade dos professores em abandonarem o "kit" da disciplina, constituído por bolas e materiais esportivos, tendo em vista que era o material que a direção da escola dispunha aos professores (Diário de campo, 03/10/12).

À luz da teoria marxista, existe um estranhamento do trabalho na sociedade capitalista (MARX, 2010) e consequente alienação do trabalho docente, na medida em que a concepção do trabalho pedagógico lhe é alijada. Especificamente no campo da Educação Física escolar, 
este alijamento passa pela negação da sua participação nos projetos de concepção e de execução dos espaços físicos destinados à prática das atividades relacionadas à disciplina.

Ao negar aos professores a possibilidade de participação no planejamento, visando à melhor forma de estruturação física do espaço escolar, as instituições de ensino acabam por proporcionarem, de forma geral, uma estruturação mais rígida, baseada majoritariamente na quadra poliesportiva, além de não se preocuparem com questões que interferem na organização diária das aulas e da própria escola. Fato comprovado por situações como, por exemplo, o número insuficiente de espaços em relação ao número de estudantes da escola e de turmas simultâneas que precisam ocupar o mesmo local:

[...] É às vezes três, quatro professores dando aula ao mesmo tempo, dividindo esse mesmo espaço com recreios e com trocentos projetos e programas que agora viraram uma febre no Brasil. [...] E aí que vem a grande ironia [...] não tem nenhum professor de educação física trabalhando em nenhum projeto desses. Não é questão de estar à frente do projeto. Esses projetos ocupam pelo menos a metade do espaço físico, do escasso espaço físico que a gente tem à disposição. A gente nunca foi consultado a respeito das atividades. (Entrevista Sílvio, 5/7/13, grifo nosso).

A inserção de projetos educacionais cria situações contraditórias no espaço escolar. Uma delas é em relação à utilização dos espaços físicos da escola para a realização de tais projetos, que são distribuídos aleatoriamente na divisão dos espaços, juntamente com as aulas de Educação Física. Do mesmo modo, tais atividades são, em sua maioria, terceirizadas ou coordenadas por voluntários, o que evidencia um processo de precarização do trabalho docente, que é uma das manifestações do processo de proletarização docente. Outro fato que identificamos é que os professores das próprias instituições escolares têm tido dificuldades para implementarem seus projetos esportivos, e, contraditoriamente, crescem o número de projetos oriundos de parcerias com o poder público e outras instituições, fazendo com que, ao passo que tais ações estejam presentes no dia a dia escolar, os professores de Educação Física estão alheios, tanto à concepção como organização, implantação e implementação de tais projetos.

\section{Organização coletiva dos professores: entre a escola e o sindicato}

Identificamos na pesquisa duas formas nas quais os professores de Educação Física se organizam coletivamente. Na escola, notamos que há dificuldade de organização conjunta, pois são reduzidos os espaços nos quais os docentes têm a possibilidade de elaborar, discutir e trabalhar conjuntamente em um projeto da área para a escola, já que perdem gradativamente espaços de planejamento coletivo, fruto de uma estrutura escolar cada vez mais burocratizada.

Entretanto, e apontando o caráter contraditório deste processo, são notáveis as formas de resistência por parte dos docentes na procura para subverter esta lógica, apresentando alternativas ao quadro, para que possam pensar e realizar o seu trabalho de forma coletiva, por exemplo, a solicitação junto à supervisão de horário específico para discutir o trabalho coletivo, ou, como cita a professora Omara, organizar-se coletivamente nas "brechas" de horários.

Essa dificuldade interfere de diversas maneiras no trabalho dos professores, principalmente porque não há um reconhecimento entre os pares. Além disso, nota-se o isolamento do seu trabalho, e principalmente, evidencia-se o distanciamento do grupo de professores da possibilidade de comporem um projeto de Educação Física para a escola.

Do ponto de vista sindical, as formas de participação e organização do professorado são bastante heterogêneas. Mostrou-se consensual a importância da organização coletiva para reivindicação de manter e ampliar direitos, ao mesmo tempo em que, em relação à 
participação efetiva, há discordâncias, por não concordarem com as formas de mobilização, seja pela descrença na mudança ou porque não se reconhecem como sendo parte de tal movimento. Exemplo disto são os relatos do professor Sílvio, que conta ter sido pequena a adesão dos colegas nas últimas greves e paralisações dos municipários.

Um dos possíveis fatores que evidenciam certo distanciamento da participação sindical possa ser a retórica do discurso sobre o profissionalismo, que, como ressalta Contreras (2002), ao comentar a discussão proposta por Densmore:

Para Densmore, por exemplo, a pretensão dos docentes de serem reconhecidos como profissionais não reflete mais que uma aspiração para fugir de sua assimilação progressiva às classes trabalhadoras. Esse fenômeno relaciona-se não só com a degradação das condições de trabalho, mas com a consequente composição social dos aspirantes a essa ocupação. [...] Essa transformação segue unida à aspiração de pertencer a um status de reconhecimento e prestígio social que sentem perder enquanto categoria e para o qual a ideia do profissionalismo, como representação de habilidades especializadas, responsabilidade e compromisso preenche perfeitamente as necessidades de diferenciação e reconhecimento social (CONTRERAS, 2002, p. 40).

Isso surge como um "nó" para o sindicalismo como um todo, já que evidencia diferença existente dentro de um mesmo grupo sindical:

Não reconheço como pares. São, mas não são. Acho que não sei se os interesses são iguais. Me parece que não. Até a questão das férias dos professores, da maneira como é, que o resto do grupo não vê com bons olhos isso, os municipários. Não tô falando especificamente disso, mas só tô dando um exemplo. Que não sou só eu que não me reconheço, eu acho que eles também não nos vêem muito assim, semelhantes (Entrevista professora Violeta, 22/08/13) [grifos nossos].

No caso específico da cidade de Porto Alegre, o grupo de professores possui condições de trabalho e salariais mais elevadas que outros grupos de trabalho do serviço público municipal. Assim, por mais que, do ponto de vista objetivo, os professores componham o grupo de proletários, subjetivamente sua consciência transita entre aqueles que se reconhecem como tal e os que se reconhecem e/ou aspiram como outro grupo.

Entretanto, é notável que, mesmo em meio a essas contradições e dificuldades, o sindicato ainda permanece como um instrumento de luta contra o processo de proletarização docente, fazendo o contraponto ao discurso oficial e tendo algumas conquistas, mesmo que sejam apenas no nível da manutenção de direitos conquistados historicamente pela classe trabalhadora. Porém, carece de repensar as estratégias de aproximação com os professores, pois estes, em boa parte dos casos, não se reconhecem nele, criticando muitas das práticas adotadas para organizar a categoria.

\section{Considerações finais}

Entendemos que a organização do trabalho pedagógico é permeada por situações contraditórias. Por um lado, há um processo de proletarização docente, materializado em situações como: divisão do trabalho em especialidades; precárias condições de trabalho; isolamento profissional; alienação/estranhamento; burocratização da escola; impossibilidade de uma organização coletiva.

Por outro lado, a partir do entendimento dialético, tais condições "são" e "não são "ao mesmo tempo. A contradição faz-se presente e seria um equívoco nosso crer que tal processo ocorresse sem resistência, seja por parte dos grupos organizados que lutam por melhores 
condições de trabalho, seja por parte dos docentes que, mesmo em frente a esse quadro, estão empenhados em superá-los no seu microcontexto.

Nossos achados mostram que os professores de Educação Física constroem seu trabalho superando diariamente as situações inerentes da escola pública inserida no contexto do mundo capitalista. É preciso, assim, fortalecer a escola pública como alternativa a esse quadro. Que seja socialmente construída e atenda aos anseios da classe trabalhadora.

Para tal, é preciso qualificá-la em recursos humanos e materiais, que proporcione aos docentes condições de trabalho e salário adequados. Também, que haja espaços institucionais para que aqueles que, diariamente constroem o ensino público, possam criar formas alternativas de educação, que esteja além da pura e simples escolarização voltada para o mercado de trabalho e que atrela índices à destinação de verbas para a escola.

Por fim, fica a sugestão para os professores, sejam iniciantes ou experimentados, que sejam o ponto de apoio da escola pública. Que, mesmo em frente a todas as dificuldades vividas, sejam o contraponto necessário na construção de outra forma de educação, que seja coletiva, superadora e que possibilite a construção de seres humanos autônomos e críticos.

\title{
THE IMPLICATIONS OF TEACHING PROLETARIANIZATION IN SCHOOL PHYSICAL EDUCATION
}

\begin{abstract}
This paper discusses the process of teacher proletarianization, more specifically in the context of Physical Education at school. From a dialectical materialist reading of education, it carried out a qualitative research with professors of the Municipal School of Porto Alegre, in which we seek to understand how teachers organize their pedagogical work against this process, which stems from the increasing approximation of teaching conditions to the characteristics of capitalist society work.

Keywords: Teaching Proletarianization; Pedagogical Work; Physical Education; Dialectical Materialism.

\section{IMPLICACIONES DE LA PROLETARIZACIÓN DEL TRABAJO DOCENTE EN LA EDUCACIÓN FÍSICA EN LA ESCUELA}

\section{Resumen}

En este trabajo se discute el proceso de proletarización docente, más concretamente en el contexto de la Educación Física en la Escuela. Partiendo de una lectura materialista dialéctica de la educación, se realizó una investigación cualitativa con profesores de la Red de Escuelas Municipales de Porto Alegre, en el cual buscamos comprender cómo los profesores organizan su trabajo pedagógico delante de este proceso, que se deriva de la creciente aproximación de las condiciones del trabajo docente con las características del trabajo de la sociedad capitalista.

Palabras clave: Proletarización Docente; Trabajo Pedagógico; Educación Física en la Escuela; Materialismo Dialéctico. 


\section{Referências}

BAKHTIN, M. Marxismo e Filosofia da Linguagem. 12.ed. Cidade da editora: Hucitec, 2006.

CONTRERAS, J. A autonomia de Professores. São Paulo: Cortez, 2002.

COSTA, A. Entre a dilapidação moral e a missão redentorista: o processo de alienação no trabalho dos professores do ensino básico brasileiro. In: COSTA, A. , FERNANDES NETO, E., SOUZA, G. A proletarização do professor: neoliberalismo na educação. São Paulo: Editora Instituto José Luís e Rosa Sundermann, 2009.

CPERS/SINDICATO. O ensino público pede socorro: pesquisa nas escolas públicas estaduais. Porto Alegre, 2010. Disponível em: $<$ http://www.cpers.org.br/ $>$. Acesso em: abril de 2013.

DAYRELL, J. A escola como espaço sócio-cultural. In: DAYRELL, J. (Org.). Múltiplos Olhares sobre educação e cultura. Belo Horizonte, MG: Editora da UFMG, v. 2000, p. 136161, 1996.

DIESAT. Condições de trabalho e saúde dos trabalhadores nas instituições de ensino privado no Rio Grande do Sul. São Paulo, 2009. Disponível em:< http://www.sinprors.org.br/>. Acesso em: maio de 2011.

FERNÁNDEZ ENGUITA, M. A ambiguidade da docência: entre o profissionalismo e a proletarização. Teoria e Educação. Porto Alegre. n. 4, p. 41-61. 1991.

FRANCO, L. A. C. A escola do trabalho e o trabalho da escola. 3.ed. São Paulo: Cortez: Autores Associados, 1988. (Coleção Polêmicas do nosso tempo; v. 22).

FREITAS, M. Organização escolar e socialização Profissional de professores iniciantes. Cadernos de Pesquisa, n. 115, p. 155-172, mar. 2002.

FRIGOTTO, G. Trabalho. In: PEREIRA, I.; LIMA, J. Dicionário da educação profissional em saúde. 2.ed. Rio de janeiro. EPSJV, 2008.

GARCIA, M; ANADON, S. Reforma educacional, intensificação e autointensificação do trabalho docente. In: Educação \& Sociedade. Campinas, vol.30, n. 106, p. 63-85, jan./abr. 2009.

MARCELO, C. Los comienzos em la docencia: Un profesorado com buenos principios. Professorado: Revista de currículum y formación del profesorado. v. 13, n. 1, 2009.

MARX, K. Engels, F. Manifesto do Partido Comunista. Coleção grandes obras do pensamento universal. Editora Escala. 2007.

MARX, K. Manuscritos econômico-filosóficos. São Paulo: Boitempo, 2010. 
MARX, K. O Capital: crítica da economia política: livro I. 30 edição. Rio de Janeiro. Civilização Brasileira, 2012.

MOLINA NETO, V. Etnografia: uma opção metodológica para alguns problemas de investigação no âmbito da Educação física. In: TRIVIÑOS, A. N. S.; MOLINA NETO, V. (Org.). A pesquisa qualitativa na educação física: alternativas metodológicas. 2.ed. Porto Alegre: Editora da UFRGS/Sulina, 2004.

MOLINA NETO, V; CONCEIÇÃO, V. da; BERNARDI, G; MOLINA, R. K. The first years of work at school: effects on identity, autonomy and training of physical education (PE) teachers. Symposium Learning to become a teacher in the contemporary world: the role of initial professional development and the first professional experiences. ECER. Istanbul. 2013.

NEGRINE, A. Instrumentos de coleta de informações na pesquisa qualitativa. In: TRIVIÑOS, A. N. B; TRIVIÑOS A pesquisa qualitativa na educação física: alternativas metodológicas. 2.ed. Porto Alegre: Editora da UFRGS/Sulina, 2004.

OLIVEIRA, DALILA. A reestruturação do trabalho docente: precarização e flexibilização. Educação e Sociedade. Campinas, vol. 25, n. 89, p. 1127-1144, set./dez. 2004.

SANTINI, J. A síndrome do esgotamento profissional: o "abandono" da carreira docente pelos professores de Educação Física da Rede Municipal de Ensino de Porto Alegre. Dissertação de Mestrado em Ciências do Movimento Humano. Escola de Educação Física, Universidade Federal do Rio Grande do Sul, 2004.

TRIVIÑOS, A. N. S. Introdução à Pesquisa em Ciências Sociais: a pesquisa qualitativa em educação. São Paulo: Atlas, 1994.

TRIVIÑOS, A. N. S. Breve introdução ao método dialético materialista na pesquisa em ciências sociais. In: TRIVIÑOS, A. N. S.; MOLINA NETO, V. (Org.). A pesquisa qualitativa na educação física: alternativas metodológicas. 3.ed. Porto Alegre: Editora da UFRGS/Sulina, 2010.

WITTIZORECKI, Elisandro. O trabalho docente dos professores de educação física na Rede Municipal de Ensino de Porto Alegre: um estudo nas escolas do Morro da Cruz. Dissertação de Mestrado em Ciências do Movimento Humano. Escola de Educação Física, Universidade Federal do Rio Grande do Sul, 2001.

Recebido em: 10/07/2015

Revisado em: 30/09/2015

Aprovado em: 01/12/2015

Endereço para correspondência:

vicente.neto@ufrgs.br

Vicente Molina Neto

Universidade Federal do Rio Grande do Sul

Av. Paulo Gama, 110, Bairro Farroupilha

Porto Alegre, Rio Grande do Sul

CEP: 90040-060 